\title{
ПРИНЯТИЕ НОВЫХ ГЕНЕРАЛЬНЫХ ПЛАНОВ ГОРОДОВ ВО ВТОРОЙ ПОЛОВИНЕ ХІХ ВЕКА (НА ПРИМЕРЕ ТОМСКОЙ ГУБЕРНИИ)
}

\section{ADOPTION OF A NEW MASTER PLANS OF CITIES AT THE SECOND HALF OF XIXth CENTURY (BY THE EXAMPLE OF TOMSK REGION)}

\author{
А.В. Сковородников, Д.С. Дегтярев \\ A.V. Skovorodnikov, D.S. Degtyarev \\ Алтайский государственный университет, \\ Россия, 656049, Алтайский край, г. Барнаул, пр-т Ленина, 61а, каб. 315 \\ Россия, 656008, Алтайский край, г. Барнаул, ул. Партизанская, 140, кв. 168. \\ Altay State University, 61a Lenin Avenue, r. 315, Barnaul, 656049, Russia \\ 140 Partisanskaya st, f. 168, Barnaul, 656008, Russia \\ E-mail: mladic@mail.ru, danildegtyarev@yandex.ru
}

\begin{abstract}
Аннотация
В условиях быстрой социальной модернизации эффективность правовых механизмов регулирования городской застройки снижается. Это хорошо видно на примере генеральных планов городов, которые долгое время являются основным государственным инструментом воздействия на процесс их развития. На материале нескольких сибирских городов второй половины XIX века проиллюстрировано нарастание несоответствия между регулирующим документом и реальной ситуацией. Основной причиной этого явления, по мнению авторов, стало отставание правовых норм и практики их применения от социально-экономического и социокультурного развития городов в условиях быстрого прогресса рыночных отношений.
\end{abstract}

\begin{abstract}
An efficiency of legal mechanisms for regulation of city development decreases during the periods of quick social transformation. It's true for general planning too as the main tool for state regulation of such processes for a long time. A rising of contradiction between general planning and real development are illustrated at the example of some Siberian cities at the $2^{\text {nd }}$ half of XIX century. Tomsk region was the most progressive part in Siberia that time, because of it was choose as an example. The quick development of market economy determined critical discrepancy between legal rules and social, economic and cultural progress in cities. It became the most important reason of inefficiency of legal instruments. As a result big Siberian cities such as Tomsk or Barnaul hadn't got adequate general plans. New documents staled earlier than established as an official rule. The same problems had Siberian towns. So some new towns such as Novo-Nikolaevsk received their plans concurrently with appearance. It was according to it development, sometimes stimulated it.
\end{abstract}

Ключевые слова: правовое регулирование градостроительства, сибирские города, Томская губерния, генеральный план.

Key words: legal regulation of building, Siberia, Siberian cities, general planning.

Современная Россия вот уже третье десятилетие находится в состоянии непрерывной социально-экономической трансформации. Некоторые специалисты обнаруживают сходство между нынешними процессами и теми, что происходили в стране во второй половине XIX века [Алисов, 2006; Гончаров, Литягина, 2009; Скубневский, Гончаров, 2007]. Поэтому они предлагают внимательнее изучить исторический опыт и проанализировать 
его. На наш взгляд, это предложение рационально и может быть отнесено почти к любой сфере жизни современного российского общества. Например, к сфере градостроительства, где в последние десятилетия наблюдается явная смена приоритетов. Хаотичная и подчас никем не контролируемая трансформация городского пространства - вот что было характерно и для второй половины XIX века, и для начала XXI века.

Впрочем, регулирование пространственного развития городов существовало уже в Древней Руси [Саваренская и др., 2004]. Однако лишь в XVIII столетии появился универсальный инструмент для этого - генеральный план города. Согласно Уставу Строительному, «город строится не иначе как по Высочайше утвержденному плану» [Устав строительный, 1876; 1896: 1915], то есть генеральный план в то время имел высшую юридическую силу в области градостроительства для данного поселения [Вайтенс, Косенкова, 2006]. В то же время, по мнению авторитетного специалиста в области истории градостроительства Т.Ф. Саваренской, «никогда еще регулирующая роль генеральных планов не была столь ничтожной, как в эпоху капитализма» (вторая половина XIX - начало XX вв.), что подтверждается многочисленными примерами [Саваренская и др., 2004; Русское градостроительное искусство, 2003]. Налицо явное противоречие между требованиями тогдашнего законодательства и реальной градостроительной практикой. Цель данного исследования - охарактеризовать значение генеральных планов городов как важнейшего правового инструмента в условиях достаточно быстрой социально-экономической трансформации.

Часто можно встретить утверждение, что в условиях раннего рыночного общества генеральные планы быстро устаревали, что и являлось главной причиной снижения их регулирующей роли [Стахеев, Ремарчук, 2008]. Поэтому мы намеренно отказались от анализа планов, принятых в дореформенное время, рассматривая только те, что были разработаны после 1861 г. В качестве эмпирической базы исследования выбрана Томская губерния. Эта территория была типичной российской провинцией со средними темпами социальной модернизации. В то же время это был самый урбанизированный район Сибири, именно здесь ярче всего проявлялись процессы модернизации городских пространств. Таким образом, Томская губерния не была ни «передовой», ни «отсталой» в смысле темпов урбанизации. Хронология исследования охватывает период с начала 60-х гг. по начало 90-х гг. XIX века.

В основе наших рассуждений лежат как уже давно существующие теории, описывающие городское пространство (например, социокультурная теория Д.А. Алисова), так и собственные авторские наработки в данной области [Дегтярев, 2018]. Мы считаем, что для раннеиндустриального этапа пространственного развития городов характерно нарастание энтропийных процессов и повышение степени вариативности развития в том или ином направлении. Для проверки данной гипотезы на конкретных примерах мы провели сравнительно-сопоставительный анализ генеральных планов, типологизацию причин их медленного введения в действие, также применили ряд методов исторической географии.

В это время были созданы 4 новых генеральных плана: в Томске, Бийске, Мариинске и Нарыме. В этом списке 1 крупный губернский город, 2 средних уездных и 1 безуездный. То есть можно говорить о тенденциях, присущих всем городам региона, а не только какой-то одной их категории. Из четырех вышеназванных городов три получили свой статус (а вместе с ним и генеральный план) еще в дореформенное время, и только для Мариинска создававшийся в это время генплан был первым (этот город был образован в 1856 г.) [Ермолаев, 2008]. Генеральный план Каинска, который был введен в действие в 1866 г., мы не рассматриваем, так как он был составлен в более ранний период - по «дореформенным» правилам.

С точки зрения дореформенного законодательства составлять генеральные планы должны были профессиональные архитекторы, а утверждать - лично император. Однако в Уставе Строительном за 1876 г. зафиксированы уже другие правила: утверждение новых планов было возложено на императора посредством министра внутренних дел (если это план губернского города) или на губернатора (если это план уездного или безуездного города). В случае, если в городе уже было введено в действие Городовое положение 1870 г., генплан должен был утвердить еще и орган городского самоуправления - Городская дума 
[Устав строительный, 1876; 1896; Лен, 2002]. Все это значительно усложняло не столько процесс составления планов, сколько процесс их ввода в действие.

На практике это выглядело так. Во второй половине 1860-х гг. было принято решение о составлении нового генерального плана Томска взамен устаревшего (принятого еще в 1830 г.). 26 января 1866 г. Томская губернская строительная комиссия рассмотрела его и в акте записала, что он «в отношении правильности составления, медицинском, торговом и полицейском оказался вполне удовлетворительным» ${ }^{21}$. В сентябре 1867 г. новый план Томска был передан на утверждение в МВД. Но при анализе его содержания оказалось, что план изобиловал ошибками и неточностями (их в общей сложности насчитали 11), поэтому он был возвращен в Томск на доработку ${ }^{22}$. Выясняя причины неудачи, инженер-архитектор Вальницкий установил, что «план настоящего расположения г. Томска, составленный господином Македонским, ... оказался составлен не вполне верно с натуры» ${ }^{23}$. В сентябре 1868 г. Губернская строительная комиссия поручила Вальницкому «вновь снять с натуры положение города Томска и согласно оному переделать проектный план», однако эти работы были перенесены на весну следующего года ${ }^{24}$. Однако уже в мае 1869 г. работы по съемке натурного плана города вновь были остановлены: Вальницкий просил себе в помощники рабочих, а оплачивать труд этих рабочих городские власти не хотели. Только в июне 1869 г. они выделили на это... целых 30 рублей! ${ }^{25}$ В итоге Вальницкий смог составить план только к осени, но теперь возникла проблема с его вычерчиванием - чертежник Никольский, на которого была возложена эта работа, оказался слишком занят другими делами ${ }^{26}$. Наконец, 3 января 1870 г. (то есть более чем через два года после начала работ по исправлению) проектный план был представлен городскому обществу. 15 февраля того же года Томская строительная комиссия новый план утвердила. И он вновь был направлен в Главное управление Западной Сибири - для экспертной оценки. Омские чиновники показали новый план Акмолинскому областному архитектору, который... нашел в нем 12 недостатков! ${ }^{27}$ Проект вновь был направлен в Томск для исправления.

В это время в Томске было введено Городовое положение, вопросами составления плана стали заниматься органы самоуправления. Работы по исправлению прежнего проекта были возобновлены только в мае 1873 г. Почти сразу же выяснилось, что проще вновь снять с натуры существующее положение зданий, чем исправлять прежний проект. Это легко объяснимо: по свидетельству городского архитектора Вальницкого в Томске в начале 1870 -х гг. строилось в среднем по 25 новых зданий в год ${ }^{28}$, за три года могло вырасти несколько новых кварталов. То есть устаревание проектов плана происходило быстрее, чем их составление. Чертежник городской управы Н. Дягилев обещал закончить работы по составлению очередного нового плана к 1 января 1874 г. Но в 1873 г. удалось инструментально снять лишь 85 кварталов города, работы продолжились и в следующем году ${ }^{29}$. Сроки окончания составления плана Томска были вновь сдвинуты. Наконец весной 1875 г. план был готов. Оставалось дело за малым - утвердить его на заседании Городской думы $^{30}$, как того требовало действовавшее на тот момент законодательство.

Городская дума решила перепроверить план еще раз. Из ее состава была выбрана комиссия, которая должна была «рассмотреть составленный проект плана: насколько он соответствует указаниям Строительного, Врачебного и Пожарного уставов и вообще лучшему

\footnotetext{
${ }^{21}$ Государственный архив Томской области (далее ГАТО). Ф. 6. Оп. 1. Д. 1591. Л. 3.

${ }^{22}$ Там же. Л. 1-2 об.

${ }^{23}$ Там же. Л. 6.

${ }^{24}$ Там же. Л. 16-17.

${ }^{25}$ Там же. Л. 30.

${ }^{26}$ Там же. Л. 70-17.

${ }^{27}$ Там же. Л. 60.

${ }^{28}$ Там же.

${ }^{29}$ Там же. Л. 98.

${ }^{30}$ Там же. Л. 101.
} 
устройству города по его местоположению» ${ }^{31}$. Комиссия приступила к работе весной 1876 г. и работала до осени того же года. Зима была потрачена на уточнение результатов работы комиссии, а также на исправление мелких недочетов. Наконец думская комиссия дала «добро», однако Дума не торопилась принимать новый план. Как сообщал губернатору Томский городской голова, «вопрос был представлен в Думу 17 мая и 9 июня сего года, но в назначенные числа собрания Думы не состоялись по неприбытии установленного числа гласных» ${ }^{32}$. Такая же ситуация повторилась и на заседании 28 июля 1877 г. И только осенью 1877 г. Городская дума рассмотрела проект... и нашла в нем недочеты. Исправить их было поручено городскому землемеру Дягилеву. На этот раз специалист работал быстро и уже в 1878 г. представил исправленный проект. 15 сентября 1878 г. из Главного управления Западной Сибири в Томск пришла долгожданная весть: новый проект, составленный Дягилевым, был рассмотрен чиновником особых поручений Эзетом и признан правильным ${ }^{33}$. Впоследствии генеральный план Томска был в 1879 г. утвержден в МВД, но вступил в силу лишь 8 марта 1883 г., когда подпись под ним поставил Александр III [Дмитриенко, 2003].

Таким образом, на составление, исправление и утверждение нового генерального плана Томска было потрачено более 17 лет. Столь длительный срок можно объяснить целым рядом причин. Во-первых, это низкое качество работ, проводимых специалистамиархитекторами. Во-вторых, это отсутствие должной поддержки таких работ со стороны властей (нехватка денег, загруженность специалистов другими делами). Это приводило к большому числу недочетов и вызывало необходимость постоянно переделывать план. В-третьих, это бюрократический подход к делу со стороны органов местного самоуправления (неявка гласных на заседания Думы, медленная работа думских комиссий и т. п.). В-четвертых, это объективное устаревание информации, отражаемой на плане. В этой связи вовсе не удивительно, что составленный и принятый с таким трудом генеральный план Томска устарел уже в начале XX века ${ }^{34}$.

Но может быть, такое длительное принятие нового генерального плана Томска связно с величиной города и с его особым статусом? Для ответа на этот вопрос предлагаем рассмотреть ситуацию с принятием генеральных планов Бийска и Нарыма, которые были составлены в эти же годы. «Проект нового генплана Бийска (взамен плана 1834 г.) был составлен и одобрен в 1868 году. Однако очень скоро стало ясно, что этот план не отвечает потребностям Бийска, так как пространственная организация поселения стремительно менялась. Фактически план 1868 года так и не был претворен в жизнь, оставшись лишь проектом. В 1878 году архитектором Таловским был разработан новый проект, позже доработанный городскими властями» ${ }^{35}$. Окончательно он был оформлен к 1885 году, и в следующем году одобрен Томским губернатором в качестве действующего генерального плана Бийска. Время, которое прошло от составления нового проекта до окончательного утверждения генерального плана, составило 18 лет [Гончаров. Литягина, 2009]. Не удивительно, что принятый в 1886 г. документ тоже потерял свою актуальность в начале XX века.

Затерянный в северных лесах небольшой городок Нарым тоже жил по генплану 1830-х годов. В соответствии с ним поселение располагалось между протоками Безымянной и Кетской и озером Полой. «Кварталы были спланированы довольно хаотично и без учета особенностей почвы. Можно сказать, что данный проект застройки города был неудачным. В 1867 году был составлен новый генеральный план города. Причиной для его принятия было стремление губернских властей спасти город от постоянных затоплений» ${ }^{36}$. Новый план сохранял сложившуюся планировку Нарыма, но здания переносились на возвышенные места. «В 1868 году была проведена разбивка жилых кварталов в количе-

\footnotetext{
${ }^{31}$ Там же. Л. 118.

${ }^{32}$ Там же. Л. 142.

${ }^{33}$ Там же. Л. 171.

${ }^{34}$ ГАТО. Ф. 196. Оп. 4. Д. 221. Л. 8.

${ }^{35}$ Государственный архив Алтайского края (ГААК). Ф. 174. Оп. 1. Д. 27. Л. 76-77.

${ }^{36}$ Государственный архив Томской области (ГАТО). Ф. 6. Оп. 1. Д. 1219. Л. 5-6.
} 
стве 32 единиц и отдельных селитебных мест в количестве 235 участков» ${ }^{37}$. Окончательно новый план был принят Нарымской городской думой в 1879 году ${ }^{38}$. Как видно из вышесказанного, даже в небольшом городе с населением менее 2 тысяч жителей между началом составления нового проекта и принятием генплана прошло 12 лет.

Таким образом, не только Томск, но и другие города губернии, которые решили изменить свои генеральные планы в пореформенное время, столкнулись с длительными задержками в этом процессе. Возможно, что основной причиной этого был вовсе не субъективный фактор, а объективные трудности, вызванные необходимостью перестраивать уже существующее городское пространство. Чтобы подтвердить или опровергнуть эту гипотезу, был рассмотрен вопрос о принятии первого генерального плана Мариинска. В этом случае мы имеем дело с планом нового города, возникшего на месте сравнительно небольшого села. То есть задача составителей плана упрощалась: нужно было построить город почти «с нуля».

В конце 50-х годов XIX века было составлено два проекта - на Кийск (так первоначально был назван новый уездный город) и на Мариинск, последний и был взят за основу ${ }^{39}$. «В течение 1860-х годов шел процесс урегулирования спорных вопросов, исправления неточностей и внесения изменений в предлагаемые в губернский Строительный Комитет проекты плана. Например, в сентябре 1869 года очередной вариант генерального плана города был забракован губернским архитектором по причине наличия в нем не менее 5 грубых градостроительных ошибок» ${ }^{40}$. Также часто расходились данные о количестве усадебной земли. В 1869 году один источник указывал, что городские строения занимают 523 десятины 842 кв. сажени, а другой - 391 десятина 1600 кв. саженей ${ }^{41}$. Наконец 1 февраля 1871 года Строительный Комитет утвердил проект генерального плана. «Однако уточнения и небольшие изменения вносились в план в течение 1870-х годов постоянно. Окончательно генеральный план Мариинска был принят Мариинской городской думой в конце 1870-х годов» [Ермолаев, 2008]. Между началом разработки проекта и утверждением генплана города и в этом случае прошло около 20 лет. Таким образом, гипотеза о трудностях, вызванных необходимостью перестраивать существующее пространство, не подтвердилась.

Сравнение процесса составления и принятия новых генеральных планов дало следующие результаты:

1. Все планы составлялись и вводились в действие очень долго - от 12 до 20 лет. За это время первоначальные проекты устаревали, что вызывало необходимость создавать новые.

2. Процесс составления новых планов осложнялся низким качеством проводимых работ, нехваткой рабочих рук, отсутствием специалистов-градостроителей. Это приводило к бесконечным исправлениям плохо составленных документов.

3. Изменение правил принятия новых генеральных планов в связи с введением Городового Положения 1870 г. еще больше удлинило процедуру, так как органы местного самоуправления затягивали принятие важных решений.

Таким образом, процедура создания и ввода в действие генеральных планов городов, которая была довольно простой и понятной в XVIII - первой половине XIX вв., в пореформенное время изменилась. Это негативно повлияло на администрирование пространственного развития городов, так как основной инструмент в этом деле (генеральный план) перестал быть эффективным. В начале XX века ситуация еще более ухудшилась: ни один из старых городов Томской губернии не принял нового генерального плана после 1886 г. Из 6 вновь возникших городов свои планы составили и утвердили только 2: Новониколаевск в 1909 г. и Камень в 1917 г. [Степанская, 2006]. В результате регулирующая

\footnotetext{
37 Там же. Л. 39.

${ }^{38}$ Там же. Л. 20.

${ }^{39}$ ГАТО Ф. 6. ОП. 1. Д. 1597. Л. 22.

${ }^{40}$ Там же. Л. 33.

${ }^{41}$ Там же. Л. 46, 73.
} 
функция генеральных планов была почти повсеместно утрачена - в связи или с отсутствием таких документов или с их безнадежным устареванием.

Можно ли считать главной причиной такого положения дел быстрый рост городов? Да, но лишь отчасти. На наш взгляд, другими причинами были субъективный фактор и изменения в законодательстве. Государство частично отказалось от регулирования градостроительного процесса, передав полномочия в этой сфере в руки местного самоуправления. Это привело к усложнению административной практики и к общему снижению эффективности управленческой работы. Вопреки распространенному мнению о полностью прогрессивном характере городской реформы 1870 г. можно утверждать, что в данном случае реформа ухудшила, а не улучшила ситуацию.

Итак, сибирские города в эпоху раннего индустриализма оказались в новой для себя ситуации. Степень государственного регулирования их пространственного развития снизилась, а на само это развитие все большее влияние стали оказывать экономические факторы. Эпоха «регулярного города» уходила в прошлое, наступал новый этап функционирования городских пространств. Принимая во внимание некоторое сходство процессов того периода и современных тенденций, можно предполагать, что и в наше время правовое регулирование застройки городов будет малоэффективным до тех пор, пока не изменится сам подход к данному вопросу.

Исследование выполнено при финансовой поддержке РФФИ в рамках научного проекта № 18-09-00439 «Алтайский историко-географический комплекс в XVIII - начале XX веков (междисциплинарные исследования и разработка информационной web-платформы)».

\section{Список литературы}

1. Алисов Д.А. 2006. Административные центры Западной Сибири: городская среда и социально-культурное развитие (1870-1914). Омск, Издательство ОмГУ, 337.

2. Вайтенс А.Г., Косенкова Ю.Л. 2006. Развитие правовых основ градостроительства в России XVIII - начала XXI веков. Обнинск, Институт муниципального управления, 525.

3. Гончаров Ю.М., Литягина А.В. 2009. Очерки истории города Бийска (вторая половина XIX - начало XX века). Барнаул, «Аз Бука», 276.

4. Дегтярев Д.С. 2018. Раннеиндустриальный этап в развитии пространства российского города (на материалах Томской губернии). Исторический курьер. 2018. 2. Статья 7, 13.

5. Дмитриенко Н.М. 2003. День за днем, год за годом: хроника жизни Томска в XVIII-XX столетиях. Томск, Издательство ТГУ, 347.

6. Ермолаев А.Н. 2008. Уездный Мариинск. 1856-1917 гг. Кемерово, Кузбассвузиздат, 743.

7. Лен К.В. 2002. Организация городского самоуправления в Западной Сибири после введения Городового положения 1870 г. Города Сибири XVIII - начала XX вв. Барнаул, Издательство АлтГУ, 152-164.

8. Русское градостроительное искусство. 2003. Градостроительство России середины XIX - начала XX века. Книга вторая. Под общ. ред. Е.И. Кириченко, М., Прогресс-Традиция, 560.

9. Саваренская Т.Ф., Швидковский Д.О., Петров Ф.А. 2004. История градостроительного искусства. Поздний феодализм и капитализм. Учебное пособие для вузов. М., Архитектура, 400.

10. Скубневский В.А., Гончаров Ю.М. 2007. Города Западной Сибири во 2-й половине XIX начале XX веков: Население. Экономика. Застройка и благоустройство, Барнаул, «Аз Бука», 292.

11. Стахеев О.В., Ремарчук С.М. 2008. Ретроспективный анализ процесса формирования градостроительной регулирующей деятельности в отечественной и мировой практике. Вестник ТГАСУ, 2 (2008), 17-26.

12. Степанская T.M. 2006. Архитектура Алтая XVIII-XX вв. Барнаул, АРT, 300.

13. Устав Строительный, измененный по продолжениям 1863-1872 гг. Издание 2-е. СПб., МВД, 1876, 182.

14. Устав строительный, измененный и дополненный узаконениями, обнародованными к 1 января 1896 г. СПб., МВД, 1896, 125.

15. Устав строительный, измененный и дополненный узаконениями, обнародованными к 1 декабря 1914 г. Петроград, МВД, 1915, 510. 


\section{References}

1. Alisov D.A. 2006. Administrativnye tsentry Zapadnoi Sibiri: gorodskaya sreda i sotsial'nokul'turnoe razvitie (1870-1914). [Administrative centers or West Siberia city tnvironment and socialculture development (1870-1914)] Omsk, OmSU, 337.

2. Vaitens A.G., Kosenkova Yu.L. 2006. Razvitie pravovykh osnov gradostroitel'stva v Rossii XVIII - nachala XXI vekov. [The development of legal foundation of city-building in Russia at the XVIII-XXI]. Obninsk, Institut munitsipal'nogo upravleniya, 525.

3. Goncharov Yu.M., Lityagina A.V. 2009. Ocherki istorii goroda Biiska (vtoraya polovina XIX nachalo XX veka) [Essays about Biysk history ( $2^{\text {nd }}$ halr of XIX - beginning or XX)]. Barnaul, Azbuka. 276.

4. Degtyarev D.S. 2018. Ranneindustrial'nyi etap v razvitii prostranstva rossiiskogo goroda (na materialakh Tomskoi gubernii) [The Early industrial stage of the Russian urban space development (on the materials of Tomsk region)] Istoricheskii kur'er. 2018. 2. Stat'ya 7, 13

5. Dmitriemko N.M. 2003. Den' za dnem, god za godom: khronika zhizni Tomska v XVIII-XX stoletiyakh [Day after day, year after year. The chronicle of Tomsk life in XVIII-XX cc.]. Tomsk, TSU, 347.

6. Ermolaev A.N. Uezdnyi Mariinsk. 1856-1917 gg. [Town Mariinsk]. 1856-1917. Kemerovo, Kuzbassvuzizdat, 743.

7. Len K.V. 2002. Organizatsiya gorodskogo samoupravleniya v Zapadnoi Sibiri posle vvedeniya Gorodovogo polozheniya $1870 \mathrm{~g}$. [An organization of municipal power in West Siberia after City Rule of 1870 introduction Goroda Sibiri XVIII - nachala XX vv. [Siberian cities in XVIII - beginning of XX cc.]. Barnaul, ASU, 152-164.

8. Russkoe gradostroitel'noe iskusstvo. 2003. Gradostroitel'stvo Rossii serediny XIX - nachala XX veka. Kniga vtoraya. Pod obshch. red. E.I. Kirichenko [Russian city-building art. City-building of Russia in the middle of XIX - the beginning of XX]. M., Progress-Traditsiya, 560.

9. Savarenskaya T.F., Shvidkovsky D.O., Petrov F.A. 2004. Istoriya gradostroitel'nogo iskusstva. Pozdnii feodalizm i kapitalizm. [History of city-building art. Last feudalism and capitalism]. Textbook for universities. M., Architecture, 400.

10. Skubnevsky V.A., Goncharov Yu.M. 2007. Goroda Zapadnoi Sibiri vo 2-i polovine XIX - nachale XX vekov: Naselenie. Ekonomika. Zastroika i blagoustroistvo [Cities of West Siberia at the $2^{\text {nd }}$ half of XIX - the beginning of XX. Population. Economy. Sprawl and accomplishment]. Barnaul, Azbuka. 292.

11. Stakheev O.V., Remarchuk S.M. 2008. Retrospektivnyi analiz protsessa formirovaniya gradostroitel'noi reguliruyushchei deyatel'nosti v otechestvennoi i mirovoi praktike [A retrospective analysis of process of creation of legal regulation of city-building in Russian and foreign practics]. Vestnik TGASU, 2 (2008): 17-26.

12. Stepanskaya T.M. 2006. Arkhitektura Altaya XVIII-XX vv. [An architecture of Altay in XVIII-XX cc.]. Barnaul, ART, 300.

13. Ustav Stroitel'nyi, izmenennyi po prodolzheniyam 1863-1872 gg. 1876. [Rule of Building, changed during 1863-1872]. Ed. 2. StP., MOI, 182.

14. Ustav stroitel'nyi, izmenennyi i dopolnennyi uzakoneniyami, obnarodovannymi k 1 yanvarya 1896 g. 1896. [Rule of Building, changed to January 1 1896]. StP., MOI, 125.

15. Ustav stroitel'nyi, izmenennyi i dopolnennyi uzakoneniyami, obnarodovannymi k 1 dekabrya 1914 g. 1915. [Rule of Building, changed to December 1 1914]. Petrograd, MOI, 510.

\section{Ссылка для цитирования статьи Link for article citation}

Сковородников А.В., Дегтярев Д.С. 2020. Принятие новых генеральных планов городов во второй половине XIX века (на примере Томской губернии). Via in tempore. История. Политология, 47(1): 113-119. DOI 10.18413/2687-0967-2020-47-1-113-119

Skovorodnikov A.V., Degtyarev D.S. 2020. Adoption of a new master plans of cities at the second half of XIXth century (by the example of Tomsk region). Via in tempore. History and political science, 47(1): 113-119 (in Russian). DOI 10.18413/2687-0967-2020-47-1-113-119 